\title{
An International Continence Society (ICS) report on the terminology for single-use body worn absorbent incontinence products
}

\author{
Mandy Fader ${ }^{1}$ (D) | Alan Cottenden ${ }^{2}$ (D) | Chris Chatterton ${ }^{3}$ | Helena Engqvist ${ }^{4}$ \\ Sharon Eustice $^{5}$ | Diane K. Newman ${ }^{6}$ (D) | Joan Ostaszkiewicz ${ }^{7}$ | \\ Mary H. Palmer ${ }^{8}$ (i) | Tara Willson? | Bernard Haylen ${ }^{10}$
}

${ }^{1}$ School of Health Sciences, University of Southampton, Southampton, UK

${ }^{2}$ Department of Medical Physics and Bioengineering, University College London, London, UK

${ }^{3}$ Independent Researcher, Berkhamstead, UK

${ }^{4}$ Independent Consultant, Jönköping, Sweden

${ }^{5}$ Bladder \& Bowel Specialist Service, Cornwall Partnership NHS Foundation Trust, Bodmin, UK

${ }^{6}$ Perelman School of Medicine, University of Pennsylvania, Philadelphia, Pennsylvania

${ }^{7}$ National Ageing Research Institute, Melbourne, Australia

${ }^{8}$ School of Nursing, University of North Carolina at Chapel Hill, Chapel Hill, North Carolina

${ }^{9}$ Patient representative, London, UK

${ }^{10}$ Faculty of Medicine, University of New South Wales, Sydney, Australia

Correspondence: Mandy Fader, School of Health Sciences, University of Southampton, Building 67, Highfield Campus, University of Southampton, Southampton SO17 1BJ, UK.

Email: m.fader@soton.ac.uk

Funding information

International Continence Society

\begin{abstract}
Aims: In 2016, the International Continence Society (ICS) Standardization Steering Committee appointed a working group to address the confusing plethora of synonyms currently used to describe single-use body worn absorbent incontinence products by recommending preferred terminology.

Methods: An online questionnaire was posted in 2016/17 inviting input from stakeholders internationally. The data were analyzed and conclusions progressively refined through working group discussions, an open meeting at the 2017 annual ICS conference, and a review of further iterations-including from the parent ICS Standardization Committee-until consensus was reached. Partway in, the International Organization for Standardization started
\end{abstract}

Mandy Fader and Alan Cottenden are Co-chairs of the Working Group.

Mandy Fader, Alan Cottenden, Chris Chatterton, Helena Engqvist, Sharon Eustice, Diane K. Newman, Joan Ostaszkiewicz, Mary H. Palmer and Tara Willson are members of the Working Group.

Bernard Haylen is Chair ICS Standardization Steering Committee.

This is an open access article under the terms of the Creative Commons Attribution-NonCommercial License, which permits use, distribution and reproduction in any medium, provided the original work is properly cited and is not used for commercial purposes.

(c) 2020 The Authors. Neurourology and Urodynamics Published by Wiley Periodicals LLC 
a project with similar scope and the two organizations liaised to harmonize their conclusions while respecting each other's processes.

Results: A hundred people from 18 countries responded to the questionnaire. About a third $(32.2 \%)$ of those declaring their nationality were from the UK and a further third (34.5\%) from other English-speaking countries. Two-thirds (67.8\%) lived in Europe; around a quarter (23\%) in North America; and 9.2\% in Australasia. Seven main design categories of products were identified and, while clear consensus was readily achieved in naming some of them, others required more work to determine the best term among multiple contenders.

Conclusions: The working group concluded that the seven product design categories should be called: (a) pads; (b) unbacked pads; (c) male pads; (d) male pouches; (e) pull-on pads (protective underwear); (f) all-in-ones (wraparound pads, adult briefs); and ( $\mathrm{g}$ ) belted pads (belted products), in which the bracketed terms are judged acceptable (though not preferred) alternatives.

\section{INTRODUCTION}

Not all bladder or bowel incontinence problems can be completely and permanently cured. The challenge for those whose symptoms persist is to discover how to deal with their incontinence to minimize its impact on their health and quality of life (QoL). And this usually includes managing urine and stool leakage using continence products. Even those whose incontinence is ultimately treated successfully may have to live with symptoms for a time-for example, while waiting for surgery, or for pelvic floor muscle training to yield its benefits-and they may use continence products temporarily during this waiting period. Others may use them as an adjunct to a treatment that reduces their leakage (eg, bladder training, toileting programs) without eliminating it. Still, others may use products intermittently, limiting their use to particular timeframes or activities associated with troublesome leakage. However, some use products permanently, either following treatment that has not been (completely) successful or because-depending on their frailty, severity of symptoms, and personal priorities-they are not candidates for treatment.

Successful management of incontinence with products is often referred to as "contained incontinence" and can bring substantial benefits to QoL even though a cure has not been achieved. ${ }^{1}$ A wide variety of such products exists but by far the most common are singleuse (as opposed to reusable/washable) body worn (that is, worn on the body as opposed to bed and chair protectors) absorbent products. The ICS defines absorbent products as "... those that have been specifically developed to help manage leakage or soiling, such as absorbent pads and pants, absorbent bed sheets and chair covers" 2 and they come in a range of different designs. The purpose of this report is to recommend terms for single-use body worn absorbent products. The primary purpose of such products is to absorb and thereby contain urine, however, some designs may also be used to contain faeces either alone or in combination with urine. There are a very small number of products made from absorbent materials that are designed specifically to contain faeces alone; these are not included within the scope of this report.

The names used to describe absorbent products can vary considerably among - and even within — countries and cultures. This has resulted in a confusing plethora of synonyms in the clinical/academic literature, ${ }^{3-14}$ as well as the literature provided by product suppliers, and information available on the internet or through other media such as magazines. Standardized terminology, providing preferred terms that all are encouraged to use, would facilitate understanding and communication among users, caregivers, clinicians, researchers manufacturers, and government agencies. To that end, the ICS appointed an international working group of experts in the field of containment with continence products to consult widely across the international community of people concerned with these products to establish a standard terminology that enjoys widespread support. The guiding principles were to identify_and recommend-for each product design category, that term most widely acceptable internationally, favoring - where possible - terms which are most helpfully descriptive of a design's characteristic features and avoiding terms with child/toddler/baby connotations.

This report summarizes the recommendations of the working group. Further, detailed Supporting Information is available on-line on the ICS website (URL to be 
determined), describing: the on-line questionnaire that was used to solicit the views of stakeholders internationally (Supporting Information, Appendix A, ICS website); the key characteristics and views of the respondents (Supporting Information, Appendices B and C, ICS website); and an International Continence Society members' consultation meeting on the topic at the 2017 annual ICS conference (Supporting Information, Appendix D, ICS website).

\section{2 | METHODOLOGY}

Drawing on their collective experience and the literature review conducted for the absorbent products section of the sixth International Consultation on Incontinence, ${ }^{1}$ the working group created an online questionnaire (Supporting Information, Appendix A, ICS website) to solicit the opinions of stakeholders internationally. The questionnaire invited respondents to identify their interest in these products (such as product user, healthcare professional, or product manufacturer) and their nationality; express their preferences for a range of offered alternative names for each of seven different categories of single-use body worn absorbent incontinence products identified by the working group; suggest-with reasons - any other alternative names worthy of consideration; and comment on proposed descriptions for the defining features and main variant features for each of the seven design categories. The final questionnaire was posted on 12 December 2016 and closed for participation on 7 March 2017, by which time 100 people from 18 countries had responded. Almost a third (32.2\%) of respondents who declared their nationality were from the UK and about a further third (34.5\%) were from other English-speaking countries. Twothirds (67.8\%) lived in Europe; around a quarter $(23 \%)$ in North America; and 9.2\% in Australasia. Details of the characteristics and views of the respondents are given in Appendices B and C (Supporting Information, ICS website).

Drawing on the survey findings, the working group drafted a set of recommendations which were presented at an open meeting at the 2017 annual conference of the International Continence Society in Florence attended by 12 experts. This meeting focused on reaching agreement on rival terms when a clear consensus was not apparent, and a report of the meeting is provided in Appendix D (Supporting Information, ICS website). Part way into this project the International Organization for Standardization (ISO) embarked on a parallel project to standardize nomenclature relating to single-use absorbent body worn products for incontinence. ICS and ISO working groups shared their draft reports and recommendations to achieve as much alignment as they could while respecting each other's processes. The

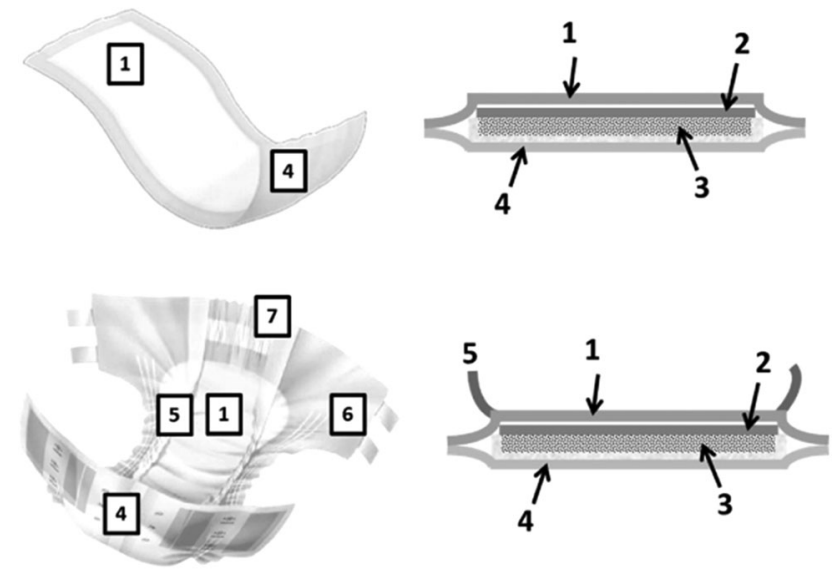

F I G U RE 1 A (top), The design of a simple pad (left) and a transverse section through it (right) to show the layered construction. B (bottom), The design of a typical all-in-one product (left) and a transverse section through it (right) to show the layered construction. 1: Topsheet; 2: Backsheet; 3:

Absorbent core; 4: Acquisition and distribution layer (ADL); 5: Standing gathers (leg cuffs); 6: Fasteners; and 7: Elastication

terminology adopted in the ISO standard currently under preparation is expected to be very similar to that described here. To complete the ICS project, working group members were invited to comment on drafts of the final report before it was deemed completed.

\section{3 | PRODUCT DESIGN FEATURES}

Although single-use (disposable) body worn absorbent incontinence products come in a variety of generic designs, they share many design features in common, as illustrated in Figure 1 and described in the following sections. These terms were used in describing the various proposed product categories in the on-line questionnaire (Supporting Information, Appendix A, ICS website), along with an invitation to respondents to identify any omissions, errors, or preferences for changes. In fact, terms and descriptions for design features turned out to be far less contentious than those for product categories, necessitating only very minor changes to draft text to arrive at the wording below.

\section{1 | Topsheet}

The topsheet in an absorbent incontinence product is the layer of fabric which lies against the wearer's skin. It is made from a water-permeable material that allows urine to pass readily through to the acquisition and distribution layer (ADL) and the absorbent core beneath. 

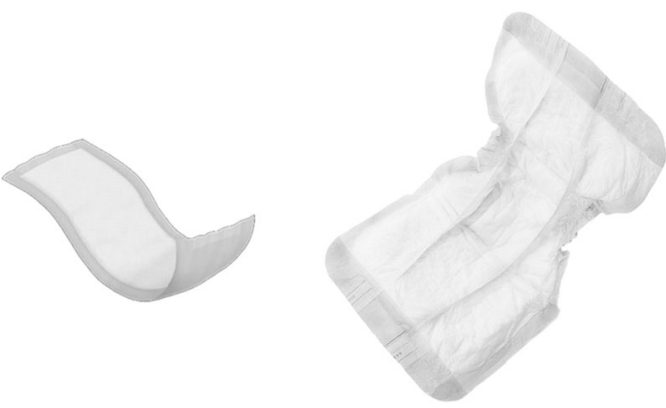

FIGURE 2 Examples of pads

\section{2 | Acquisition and distribution layer}

Absorbent incontinence products often have an ADL between the topsheet (above) and the absorbent core (below). The ADL is designed to allow urine to enter the product rapidly, and spread it over a large area of absorbent core. It is not intended to absorb urine itself.

\section{3 | Absorbent core}

The absorbent core of an absorbent incontinence product is where urine is captured and stored. It is made from (a) material(s) which absorb(s) urine readily and retains it under pressure, such as when the wearer changes posture or position.

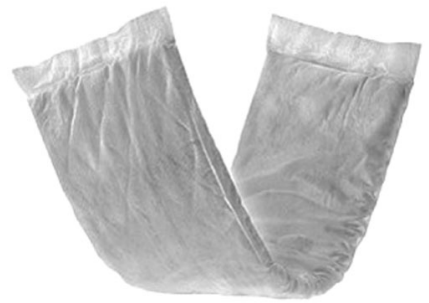

FIGURE 3 An example of an unbacked pad

\subsection{Backsheet}

The backsheet in an absorbent incontinence product is a layer of waterproof material which forms the outside surface of the product, away from the wearer's body. It may be breathable.

\section{5 | Fasteners}

Fasteners (Tabs) enable the front and back regions of all-in-ones and belted pads to be secured to one another, helping to hold the product in the intended shape and enable a close fit to the wearer. Fasteners/tabs are most commonly faced with an adhesive (which usually allows them to be undone and refastened to achieve the desired fit) or a hook and loop fastening system.

TABLE 1 Total, new, and changed definitions (from those currently in the ICS Glossary)

\begin{tabular}{llll} 
Section & New definitions/descriptors & Changed definitions/descriptors & Total \\
\hline Introduction \& methodology & 4 & 0 & 4 \\
\hline Product design features & 7 & 0 & 7 \\
\hline Terms for product design categories & 7 & 0 & 7 \\
Total & 18 & 0 & 18
\end{tabular}

Abbreviation: ICS, International Continence Society.

TABLE 2 The defining features and main variant features of pads

Defining features
$\begin{aligned} & \text { Waterproof-backed absorbent products that are held in place using separate, close-fitting (regular or specially } \\ & \text { designed) underwear }\end{aligned}$
Main variant features $\quad \begin{aligned} & \text { - Products may be used by either sex, but some are intended (by their color, style, shape, or the placing of } \\ & \text { absorbent material, for example) just for men or just for women. } \\ & \text { - Products come with different absorption capacities. } \\ & \text { - Longitudinal elastic side barriers and leg cuffs on either side of the crotch may be included to improve fit, } \\ & \text { comfort, and prevent leakage. } \\ & \text { - Products may have an adhesive strip on the back or adhesive wings to the sides to help secure them in } \\ & \text { underwear. } \\ & \text { - Products may have a wetness indicator. } \\ & \text { - Products may or may not be suitable for containing fecal incontinence (FI) as well as urinary } \\ & \text { incontinence (UI). }\end{aligned}$


TABLE 3 The defining features and main variant features of unbacked pads

Defining features $\begin{array}{r}\text { Absorbent products without a waterproof backing used either (a) inside another product such as a category } 6 \\ \text { product to supplement its absorption capacity or to reduce the frequency with which it needs to be changed } \\ \text { (the unbacked pad may be changed with relative ease, without necessarily needing to also change the outer } \\ \text { product), or (b) on its own, secured using separate, close-fitting, underwear which itself includes } \\ \text { waterproofing in the pad area }\end{array}$
Main variant features
- Products may be used by either sex.
- Products may be rectangular or contoured to better fit the wearer.
- Products come with different absorption capacities.
- Products may or may not be suitable for containing FI as well as UI.

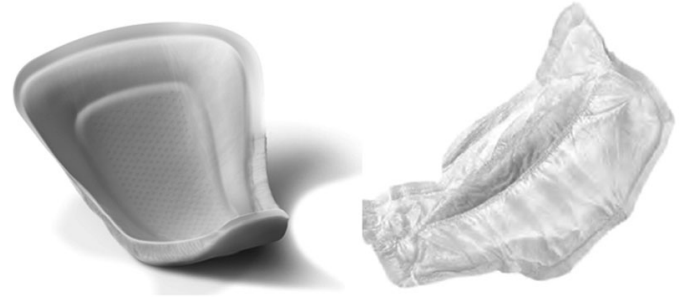

FIGURE 4 Examples of male pads

\section{6 | Elastication}

Elastication is often used to give an incontinence product the desired shape and to achieve a close fit with the wearer. It is commonly used in the waist belts of all-in-ones (wrap-arounds, adult briefs), pull-on pads (protective underwear), and belted pads (belted products). In pull-on pads, it may be used across much of the area of the product. It is used along the edges of the crotch region in many different designs.

\section{7 | Leg cuffs}

Leg cuffs (standing gathers) refer to a particular kind of elastication which may be used longitudinally on a
FIGURE 5 An example of a male pouch

product near the edges of the crotch region to promote close contact with the groin on either side of the body.

\section{4 | RECOMMENDED TERMS FOR PRODUCT DESIGN CATEGORIES}

Single-use body worn absorbent products can be divided into seven distinct categories according to their main (defining) features. A recommended name for each design category is given below, along with descriptions of its defining — and main variant-features.

TABLE 4 The defining features and main variant features of male pads

Defining features

Waterproof-backed absorbent products for men that are designed to cover the penis and scrotum, and are held in place using separate, close-fitting (regular or specially designed) underwear

Main variant features
- Products come with different absorption capacities.

- Longitudinal elastic side barriers and leg cuffs at the sides may be included to improve fit and comfort and prevent leakage.

- Products may have an adhesive strip on the back to help secure them in underwear. 
TABLE 5 The defining features and main variant features of male pouches

\begin{tabular}{|c|c|}
\hline Defining features & $\begin{array}{l}\text { Waterproof-backed absorbent products for men, fashioned into a pocket into which the penis-and sometimes } \\
\text { the scrotum, too-is placed. They are held in place using separate, close-fitting (regular or specially } \\
\text { designed) underwear }\end{array}$ \\
\hline Main variant features & $\begin{array}{l}\text { - Products come with different absorption capacities. } \\
\text { - Products may have an adhesive strip on the back to help secure them in underwear. } \\
\text { - Products may have a hook and loop fastening system or adhesive tape to secure the product round the penis. }\end{array}$ \\
\hline
\end{tabular}
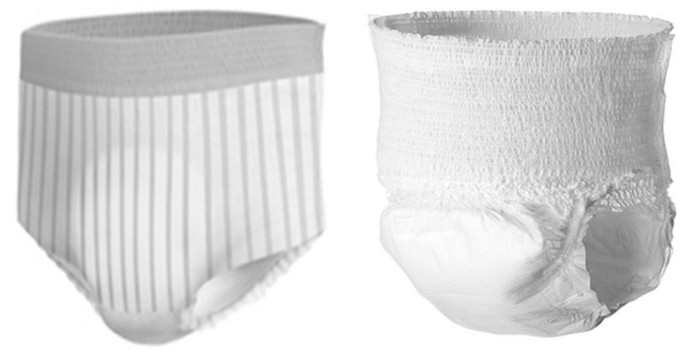

F I G U RE 6 Examples of pull-on pads (protective underwear)

\section{1 | Pads}

We recommend that products of the kind shown in Figure 2 should be called pads-waterproof-backed absorbent products that are held in place using separate, close-fitting (regular or specially designed) underwear. The defining features of pads and the main variant features are described in Table 1 , while the construction of a simple variant is shown in Figure 1A. Although the online questionnaire found clear international consensus in favor of pad, two alternative names (insert and liner) were popular in some countries, but never more popular than pad (Supporting Information, Appendix C: Figure C-1 and Table C-1, ICS website). Accordingly, use of these two terms-and others favored by small groups of respondents-is discouraged Table 2 .

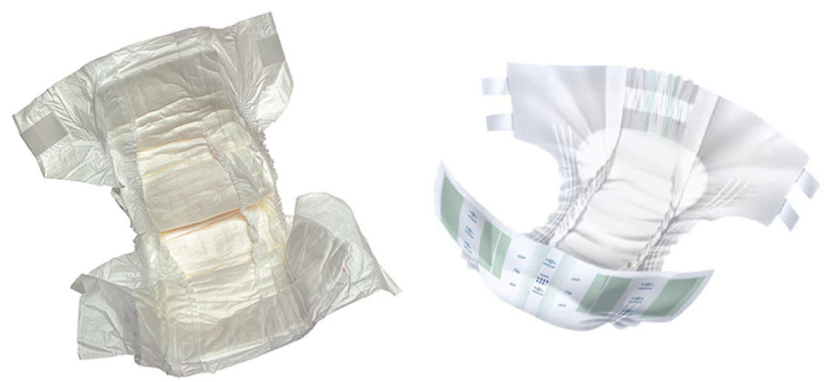

FI G URE 7 Examples of all-in-ones (wrap-around pads, adult briefs)

\section{2 | Unbacked pads}

We recommend that products of the kind shown in Figure 3 should be called unbacked pads-absorbent products without a waterproof backing. They comprise an absorbent core held in an envelope of water-permeable material and their defining features and main variant features are described in Table 3. The online questionnaire found clear international consensus in favor of booster pad. However, in Asia, it is common to use such pads, not so much to boost the absorption capacity of another product as to reduce the frequency with which it needs to be changed. An unbacked pad may be changed relatively easily without the need to also change the outer product. It is also known that pads (Section 4.1) may be used as "booster" pads and this term may, therefore, be confusing. Accordingly, unbacked pads are favored, a term which was also accepted

TABLE 6 The defining features and main variant features of pull-on pads (protective underwear)

Defining features Products in which the absorbent core, waterproof backing, and the means to hold it in place are combined in a single design resembling regular underwear. Elastic linings around the waist and hips help give a close fit

Main variant features

- Products may be used by either sex, but some are intended (by their color, style, or the placing of absorbent material, for example) just for men or just for women.

- Products come with different absorption capacities, and fit different body sizes.

- Longitudinal elastic side barriers and leg cuffs on either side of the crotch may be included to improve fit and comfort and prevent leakage.

- In some designs, side seams can be torn away for easy removal.

- Products may have wetness indicators.

- Products may or may not be suitable for containing FI as well as UI. 
TABLE 7 The defining features and main variant features of all-in-ones (wrap-around pads, adult briefs)

Defining features $\begin{aligned} & \text { One-piece products in which the absorbent core and the means to hold it in place are combined in a single } \\ & \text { design, secured using adjustable adhesive tabs or a hook and loop fastening system at the sides }\end{aligned}$
Main variant features $\quad$ - Products may be used by either sex, but some are intended (by their color, style, or the placing of absorbent
material, for example) just for men or just for women.
- Products come with different absorption capacities, and to fit different body sizes.
- Longitudinal elastic side barriers and leg cuffs on either side of the crotch may be included to improve fit
and comfort and prevent leakage.
- Products may have wetness indicators.
- Products may or may not be suitable for containing FI as well as UI.

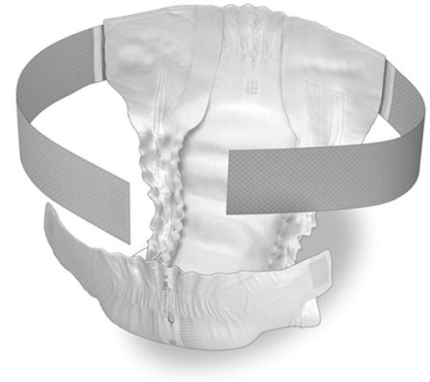

FI G URE 8 Example of a belted pad (belted product)

internationally (Supporting Information, Appendix C: Figure C-2 and Table C-2, ICS website).

\section{3 | Male pads}

We recommend that products of the kind shown in Figure 4 should be called male pads-waterproof-backed absorbent products for men that are designed to cover the penis and scrotum, and are held in place using separate, close-fitting (regular or specially designed) underwear. Although they are shaped differently, they generally include a series of material layers similar to those shown in the pad in Figure 1A. The defining features of male pads and the main variant features are described in Table 4. The online questionnaire found a clear international consensus in favor of male pad. Guard pad was quite a popular alternative in some countries but it was more popular than male pad in only one (Canada), though only marginally (Supporting Information, Appendix C: Figure C-3 and Table C-3, ICS website) Accordingly, the use of the term guard pad for men-and others favored by small groups of respondentsis discouraged.

\section{4 | Male pouches}

We recommend that products of the kind shown in Figure 5 should be called male pouches-waterproof-backed absorbent products for men, fashioned into a pocket into which the penis-and sometimes the scrotum, too-is placed. Although they are shaped differently, they generally include a series of material layers similar to those shown in the pad in Figure 1A. The defining features of male pouches and the main variant features are described in Table 5. The online questionnaire found clear international consensus in favor of pouch and no other term emerged as a popular alternative (Supporting Information, Appendix C: Figure C-4 and Table C-4, ICS website). We subsequently made the minor modification of "pouch" to "male pouch" to i mprove alignment with the conclusions of the parallel ISO project.

TABLE 8 The defining features and main variant features of belted pads (belted products)

\footnotetext{
Defining features $\quad$ One-piece products in which the absorbent core, waterproof backing, and the means to hold it in place are combined in a single design, secured by means of an adjustable belt with adhesive tabs or a hook and loop fastening system

Main variant features

- Products may be used by either sex, but some are intended (by their color, style, or the placing of absorbent material, for example) just for men or just for women.

- Products come with different absorption capacities, and to fit different body sizes.

- Longitudinal elastic side barriers and leg cuffs on either side of the crotch may be included to improve fit and comfort and prevent leakage.

- Products may have wetness indicators.

- Products may or may not be suitable for containing FI as well as UI.
} 
T A B L E 9 Recommended, acceptable alternative and "retired" terms for the seven categories of single-use body worn absorbent products for incontinence

\begin{tabular}{llll} 
Design category \# & Recommended term & $\begin{array}{l}\text { Acceptable alternative } \\
\text { term(s) }\end{array}$ & “Retired “ term(s) \\
\hline 1 & Pads & $\ldots$ & Inserts, liners, shields, slips \\
\hline 2 & Unbacked pads & $\ldots$ & Booster pads \\
\hline 3 & Male pads & $\ldots$ & Guard pads for men; shields, leafs \\
\hline 4 & Male pouches & $\ldots$ & $\ldots$ \\
\hline 5 & Pull-on pads & Protective underwear & Pant-designs, pull-ups, underwear designs, \\
\hline 6 & & & up-and-gos \\
\hline 7 & All-in-ones & Wrap-around pads ${ }^{\text {a }}$, adult briefs & Briefs, diapers, slips \\
\hline
\end{tabular}

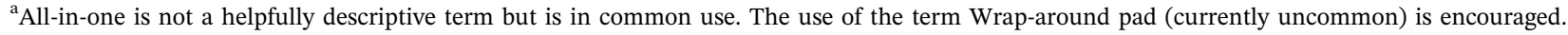

\section{5 | Pull-on pads (protective underwear)}

We recommend that products of the kind shown in Figure 6 should be called pull-on pads-products in which the absorbent core, waterproof backing, and the means to hold it in place are combined in a single design resembling regular underwear, with protective underwear as an acceptable alternative. Although they are shaped differently and have no need of fasteners, they generally include a series of material layers similar to those shown in the all-in-one in Figure 1B. The defining features of pull-on pads (protective underwear) and the main variant features are described in Table 6. The terms protective underwear and pull-up were each supported by about the same number of respondents in the questionnaire, but protective underwear was favored over pull-up (or equal to it) in all countries except the UK and Ireland (Supporting Information, Appendix C: Figure C-5 and Table C-5, ICS website) However, protective underwear is not a usefully descriptive term, and pull-up has child/toddler connotations. Thus, the term, Pull-on pads, is proposed as being descriptive of the key characteristic of the design while avoiding child/toddler connotations, with protective underwear as an acceptable alternative.

\section{6 | All-in-ones (wrap-around pads, adult briefs)}

We recommend that products of the kind shown in Figure 7 should be called all-in-ones-one-piece products in which the absorbent core and the means to hold it in place are combined in a single design, secured using adjustable adhesive tabs or a hook and loop fastening system at the sides, for the time being. Although in common use this term does not provide a helpful description of the product and we, therefore, encourage the use of the alternative more descriptive term, wrap-around pads. Adult brief is also an acceptable alternative but lacks helpful description and is, therefore, not encouraged. The construction of a typical all-in-one product is shown in Figure 1B, while the defining features of all-in-ones and their main variant features are described in Table 7. The online questionnaire revealed a diversity of views on what category 6 products should be called. Respondents from four countries favored diaper, but many others were against the term because of its connotations to infants. Slip and wraparound were favored in the Netherlands but enjoyed little support elsewhere. Adult brief was favored by Canada, the United States, and Norway but, again, there was little support elsewhere. All-in-one was favored by Australia, Belgium, and the UK and had the highest number of respondents favoring it (note: the UK was strongly represented-about a third of respondents) (Supporting Information, Appendix C: Figure C-6 and Table C-6, ICS website). In conclusion, we recommend that these products should be called all-in-ones. However wrap-around pads and adult briefs are acceptable as alternatives.

\section{7 | Belted pads (belted products)}

We recommend that products of the kind shown in Figure 8 should be called belted pads-one-piece products in which the absorbent core, waterproof backing, and the means to hold it in place are combined in a single design, secured by means of an adjustable belt with adhesive tabs or a hook and loop fastening system, with belted products as an acceptable alternative. Although they are shaped and secured differently, belted pads generally include a series 
of material layers similar to those shown in the all-in-one product in Figure 1B. The defining and main variant features of belted pads (belted products) are described in Table 7. The online questionnaire found clear international consensus in favor of belted products, which was the (joint) top choice in most countries (Supporting Information, Appendix C: Figure C-7 and Table C-7, ICS website). However, "product" is rather vague, and we recommend that "pad" should be used instead, with belted product as an acceptable alternative Table 8 .

\section{8 | Summary}

The recommended terms for the seven categories of single-use body worn absorbent products for incontinence are gathered in Table 9, along with acceptable alternatives and retired terms; that is, terms recommended for discontinuation.

\section{ACKNOWLEDGMENTS}

We are pleased to acknowledge Jenny Ellis' excellent work in administering the project and-with Dominic Turner-creating a viable online questionnaire. We are grateful, too, to Helena Engqvist who gathered all the diagrams and much of the written content for the questionnaire. The working group had no virtual or physical meetings but-by email-contributed actively to the editing of around 20 drafts of questionnaires and reports. We are grateful to Pierre Conrath (at the time, External Relations and Sustainability Director at EDANA [the International Association Serving the Nonwovens and Related Industries]) for useful advice on developing the on-line questionnaire on which the study was based.

\section{ORCID}

Mandy Fader (D) http://orcid.org/0000-0002-0801-543X Alan Cottenden (i) http://orcid.org/0000-0001-5575-115X Diane K. Newman (1) http://orcid.org/0000-0002-

5083-6397

Mary H. Palmer (D) http://orcid.org/0000-0002-3849-5577 Bernard Haylen (D) http://orcid.org/0000-0001-5436-2435

\section{REFERENCES}

1. Fonda D, Abrams P. Cure sometimes, help always-a "continence paradigm" for all ages and conditions. Neurourol Urodyn. 2006;25(3):290-292.

2. Bo K, Frawley H H, Haylen BT, et al. An International Urogynecological Association (IUGA)/International Continence Society (ICS) joint report on the terminology for the conservative and non-pharamacological management of female pelvic floor dysfunction. Neurourol Urodyn. 2017;36(2):221-244.
3. Cottenden A, Fader M, Beekman D, et al. Management with Continence Products. In: Abrams P, Cardozo L, Wagg A, Wein A, eds. "Incontinence". Sixth edition. Bristol: International Continence Society; 2017:2303-2426.

4. Fader M, Cottenden A, Getliffe K, et al. Absorbent products for urinary/faecal incontinence: a comparative evaluation of key product designs. Health Technol Assess. 2008;12(29):iii-iv-ix-185.

5. Shigeta Y, Nakagami G, Sanada H, Konya C, Sugama J. Factors influencing intact skin in women with incontinence using absorbent products: results of a cross-sectional, comparative study. Ostomy Wound Manage. 2010;56(12):26-28-30-33.

6. Bliss DZ, Lewis J, Hasselman K, Savik K, Lowry A, Whitebird R. Use and evaluation of disposable absorbent products for managing fecal incontinence by community-living people. $J$ Wound Ostomy Continence Nurs. 2011;38(3):289-297.

7. Tamai N, Kaitani T, Takehara K, Oe M, Nagase T, Murayama R. Evaluation of skin temperature humidity and comfort of two types of absorbent products for urinary incontinence. J Japanese Soc Wound Ostomy Continence Manag. 2012;16:345-352.

8. Sugama J, Sanada H, Shigeta Y, Nakagami G, Konya C. Efficacy of an improved absorbent pad on incontinence-associated dermatitis in older women: cluster randomized controlled trial. BMC Geriatr. 2012;12:22.

9. Fader MJ, Cottenden AM, Gage HM, et al. Individual budgets for people with incontinence: results from a "shopping” experiment within the British National Health Service. Health Expect. 2012;17(2):186-196.

10. Gray M, Beeckman D, Bliss DZ, et al. Incontinence-associated dermatitis: a comprehensive review and update. $J$ Wound Ostomy Continence Nurs. 2012;39:61.

11. Clarke-O'Neill S, Farbrot A, Lagerstedt Eidrup M-L, Cottenden A, Fader M. An exploratory study of skin problems experienced by UK nursing home residents using different pad designs. J Wound Ostomy Continence Nurs. 2015;42(6):621-631.

12. Gray M, Kent D, Ermer-Seltun J, McNichol L. Assessment, selection, use, and evaluation of body-worn absorbent products for adults with incontinence: a WOCN Society Consensus Conference. J Wound Ostomy Continence Nurs. 2018;45(3): 243-264. https://doi.org/10.1097/WON.0000000000000431

13. DeMarinis M, Kaschak TR, Newman DK. Absorbent products for incontinence. In: Newman DK, Rovner ES, Wein AJ, eds. Clinical Application of Urologic Catheters and Products. Switzerland: Springer International Publishing; 2018:149-172.

14. Yearwood Martin C, Murphy C, Cotterill N, Williams S, Cottenden A, Fader M. Development and psychometric evaluation of ICIQ-PadPROM: a quality of life questionnaire to assess the treatment effect of absorbent continence products. Neurourol Urodyn. 2018;37(5):1650-1657. https://doi.org/10.1002/nau.23389

How to cite this article: Fader M, Cottenden A, Chatterton $\mathrm{C}$, et al. An International Continence Society (ICS) report on the terminology for singleuse body worn absorbent incontinence products. Neurourology and Urodynamics. 2020;39: 2031-2039. https://doi.org/10.1002/nau.24488 